\title{
La evaluación de políticas públicas en El Salvador. Breve reflexión
}

Miguel Ángel Pérez $\bigcirc$.

Catedrático de Facultad de Maestrías y Estudios de Postgrado Utec

\section{RESUMEN}

Según el análisis costo-beneficio, evaluar intervenciones públicas es oneroso. Pero resulta mucho más caro no evaluarlas o hacerlo sin criterio de eficiencia, justificado este por la magnitud de los recursos que se comprometen y por los impactos que dichas intervenciones generan.

¿Podemos darnos el lujo de gastarnos los recursos públicos en políticas públicas que no funcionan?

on esta pregunta inicia la introducción de su artículo "Evaluación de políticas públicas", Marcos Vera Hernández (2010), de University College London \& Institute for Fiscal Studies. El autor argumenta su inquietud en el hecho de que, frente al cada vez más sombrío panorama de las finanzas públicas, es imperiosa la necesidad de asegurarnos de que las políticas públicas tengan el impacto positivo de ellas esperado.

Esa pregunta es mucho más pertinente para países como El Salvador, en donde la situación financiera del Estado es apremiante y, además, lograr recursos alternativos ha requerido niveles de endeudamiento más que preocupantes, porque comprometen no solo un alto porcentaje del producto interno bruto PIB, sino a las actuales y futuras generaciones. Según el Banco Central de Reserva, hasta agosto del año en curso, el saldo total de la deuda ascendió a \$11.246.0 millones. Esta cantidad es la mitad ${ }^{1}$ del PIB que genera el país, y equivale a que cada uno de los 5.7 millones de salvadoreños debiera \$1.930.

Según el Banco Mundial y el BID, en un escenario descrito como peor, el país podría llegar a incrementar su deuda hasta en un 64\% (el FMI lo ubica en un 72\%) si la economía crece con debilidad, no se hace la reforma fiscal completa para aumentar los ingresos y si se pospone o no se recorta el gasto, sobre todo con los subsidios.

Ese contraste entre la paupérrima capacidad financiera del Estado para financiar políticas públicas y las crecientes necesidades que con ellas se busca satisfacer, precisa contar con mecanismos adecuados para la formulación y evaluación de

\footnotetext{
1 Para el Fondo Monetario Internacional, una deuda igual al 50\% del PIB es el techo máximo para asegurar que la política fiscal responda al nivel de deuda sin tantas complicaciones.
} 


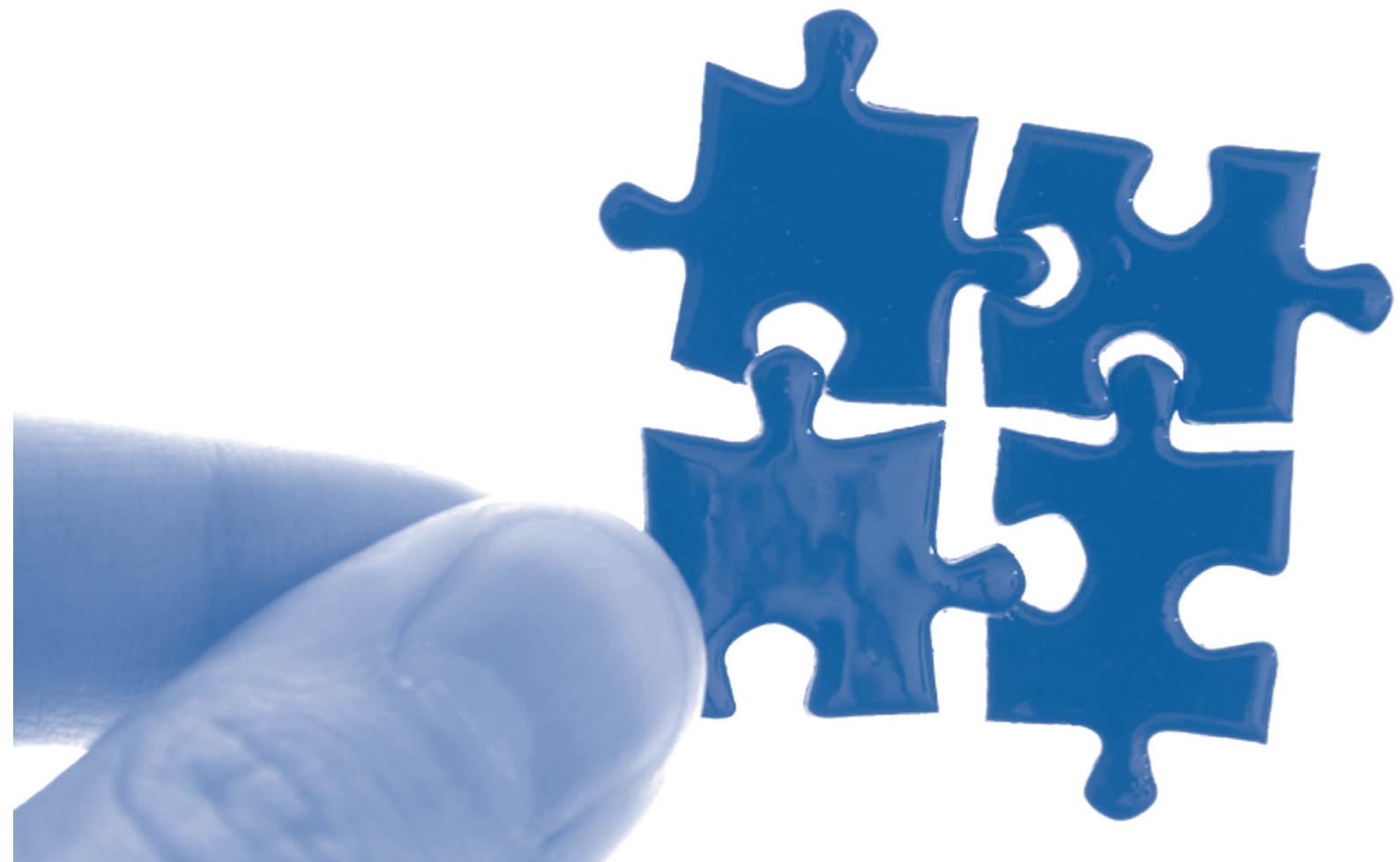

dichas políticas. Pero esto supone tener meridianamente claro qué significa este tipo de evaluación, conocer sus propósitos y utilizar la metodología adecuada para cada caso.

La evaluación está presente desde la concepción de la idea de una intervención pública. El estudio del ciclo del proyecto ilustra claramente que la evaluación se ubica en todas las fases del ciclo. Hay una evaluación exante, que se realiza en la fase de preinversión; están la evaluación intermedia o expost a nivel de seguimiento (o durante la operación) y la evaluación expost al final de la vida útil del proyecto (Castro y Mokate, 2010).

\section{Significado y propósitos de la evaluación}

Según Joint Committee Standard Education (Ysa, 2010) la evaluación consiste en "recoger y analizar sistemáticamente una información para poder determinar el valor o mérito de una intervención". Para el caso de las políticas públicas, Xavier Ballart (Ysa, 2010) la define como "producción de información que sir- va a los gestores públicos para tener una idea sobre la calidad de los servicios que están produciendo, en función de lo que se estime como valor".

Para Ballart (Ysa, 2010), la evaluación, como técnica, busca producir información útil a las administraciones públicas, para mejorar tres aspectos fundamentales: a) los procesos de decisión y planificación, b) el funcionamiento y la gestión de las operaciones diarias y c) los resultados finales en relación con los recursos invertidos.

Feinstein (2007) considera que la evaluación se realiza con dos propósitos clave: a) para aprender de la experiencia y b) para la rendición de cuentas al público o a quien financió la política. El primer propósito se logra con las llamadas evaluaciones formativas, que tienen como objetivo el aprendizaje. La rendición de cuentas caracteriza a las evaluaciones sumativas, que emiten juicio sobre el valor de lo evaluado. 
Según Ysa Tamyko (2010), los propósitos de la evaluación pueden resumirse en tres elementos clave:

\section{Comprensión, ilustración (enlightenment)}

Como su nombre lo indica, busca ilustrar, aclarar, dar luz, comprender qué está sucediendo y cómo funciona la intervención.

\section{Mejora (improvement)}

Es una forma de retroalimentar sobre las intervenciones realizadas. Es un modo de mejorar y progresar. Por eso, la evaluación es un proceso de aprendizaje de la propia intervención.

\section{Rendimiento de cuentas (accountability)}

Es un concepto amplio, no limitado exclusivamente a los aspectos económicos, sino también a la responsabilidad social y política. Más, si las actividades derivadas de la política pública son financiadas con fondos públicos, pues el contribuyente tiene derecho de saber en qué y cómo se está usando el dinero público.

La importancia de esos propósitos es indiscutible. Más aún en un entorno en donde no hay lo que los expertos denominan una "cultura de proyectos", entendida esta como la situación en la que se cuenta con las herramientas, los métodos, las técnicas y los criterios para formular y evaluar intervenciones (programas, políticas y proyectos), y donde existe la práctica cotidiana de utilizarlos para formular, preparar y evaluar dichas intervenciones.

Como rezan los dichos populares: "Algo es algo" y "De algo a nada, peor es nada". Sin el ánimo de caer en el conformismo académico, técnico o de otro tipo, eso es lo que puede afirmar- se en el área de las políticas públicas cuando se examina hasta qué punto se ha avanzado en esa "cultura de proyectos".

En El Salvador, donde la gran ausente ha sido la práctica de la transparencia o, por lo menos, la costumbre de transparentar el manejo de fondos públicos, se observa ahora un fuerte énfasis en el tercer propósito: la rendición de cuentas. Esto está muy bien, pero no es suficiente, ni para cumplir los propósitos indicados ni para preciarse de que las políticas públicas son formuladas y evaluadas con criterios de eficiencia. ${ }^{2}$

Claro que "algo es algo", pero no puede reducirse la evaluación de políticas públicas al propósito único de accountability. Más endeble se muestra esta práctica en El Salvador, al ver al subsecretario de Transparencia en una reciente entrevista televisiva, afirmando que esa dependencia no tiene carácter fiscalizador, sino más bien promotor de la rendición de cuentas. Esto, de ninguna manera descalifica el valioso trabajo que realizan en esa instancia gubernamental. Por eso es que "de algo a nada, peor es nada". Y debe aclararse que la cita de estos sabios dichos populares no es irónica, ni sarcástica. Es una realidad que debe aceptarse para partir de ella y cambiarla, mejorarla.

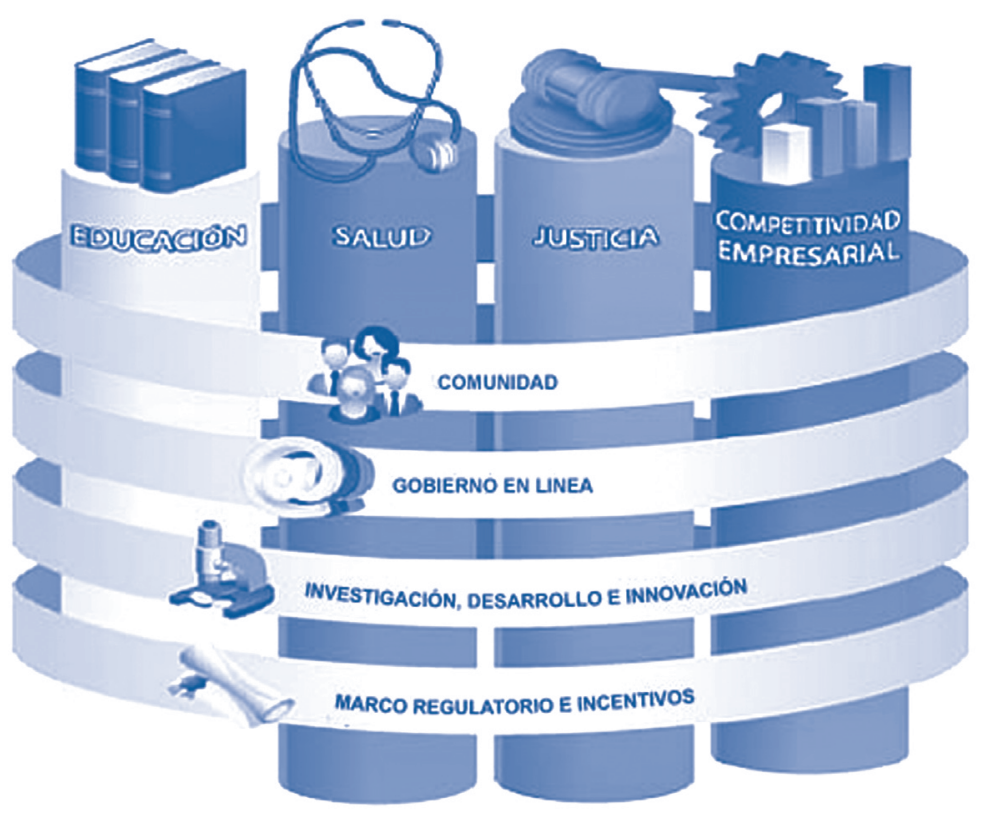

2 Una asignación eficiente conduce al mayor nivel de bienestar posible, dados los recursos disponibles, en un determinado momento. 


\section{El Salvador y el estado del arte de la evalua- ción de políticas públicas}

A pesar de lo pesimista que parezca lo planteado previamente, felizmente también hay buenas nuevas. Y no nuevas como adjetivo calificativo, porque sean tan recientes, sino buenas nuevas como sustantivo.

La primera buena nueva es que sobre formulación y evaluación de políticas públicas hay una vasta literatura, en donde se encuentra una amplia diversidad de metodologías, desde las más sencillas y menos formales hasta las más complejas (no necesariamente por difíciles o complicadas, sino por completas) y muy formales. Lo más interesante es que la literatura no se reduce a la teoría. Hay una mucho más amplia que muestra aplicaciones prácticas, concretas, de esas herramientas, a casos y situaciones específicas.

Otra buena nueva: dentro de estas metodologías abundan las aplicadas y aplicables a realidades como la salvadoreña. Esto es importante destacarlo, porque muchas veces, en las aulas, en los foros, en las discusiones académicas, etc., se escucha afirmaciones como estas: son metodologías que no aplican para nuestro país, están hechas para países donde fueron creadas, no se cuenta con la información necesaria, la evaluación no se puede reducir a fórmulas matemáticas, los modelos simplifican mucho a la realidad, los proyectos y las políticas sociales tienen beneficios obvios y no importa si a estos no se les puede medir, etc.

Después de revisar esas afirmaciones y contrastarlas con los grandes avances en la materia aquí analizada, es posible que Ios motivos para no aplicarlos sean, entre otros: $1^{\circ}$.) Improvisación de las intervenciones; $2^{\circ}$.) Utilización de criterios políticos para formularlas y seleccionarlas; $3^{\circ}$.) Compromisos adquiridos con la "clientela electoral"; 4.) Desinterés (derivado de las anteriores) y falta de voluntad política para contar con herramientas técnicas y $5^{\circ}$.) Carencia de personal conocedor, calificado y especializado en estas metodologías.

Un ejemplo, para argumentar, del segundo al quinto de los motivos citados, es la carencia del cálculo de razones precio cuenta $(\mathrm{RPC})^{3}$ o precio eficiencia para El Salvador, útiles para convertir los flujos de fondos en flujos de beneficios y costos económicos, pues son los factores de conversión de los precios de mercado a precios cuenta. ${ }^{4}$ Estos últimos reflejan la expresión de valor en términos del bienestar nacional, por lo que son usados para valorar impactos sobre ese bienestar. Pero en un país donde los criterios de asignación de recursos no son de eficiencia, ¿valdrá la pena invertir en estudios serios (y además caros) para calcular esas razones?

Otra evidencia que respalda la validez del quinto motivo, es la dificultad para focalizar los subsidios. Para El Salvador, esta es una tarea pendiente en materia de asignación de recursos y evaluación de políticas públicas. Pero no solo los gobiernos (el actual y los anteriores) han mostrado esa falencia, sino también las instituciones de investigación, los centros de pensamiento, las gremiales empresariales, etc., que no han aparecido con una propuesta en esta línea. Los programas de estudio de la carrera de economía en El Salvador, y quienes los desarrollan, también tienen su cuota de responsabilidad en esto.

\section{A manera de conclusión}

La evaluación es importante, y debe realizarse para verificar el éxito o el fracaso de las políticas públicas. Es fundamental para aprender de la experiencia y mejorar el proceso de toma de

\footnotetext{
3 Otro ejemplo similar es el cálculo de la disposición a pagar (DAP) para intervenciones específicas, muy útil para la valoración de impactos de políticas ambientales.

${ }^{4}$ Cuando estos precios incluyen efectos distributivos de las políticas, se convierten en precios sociales, usados para realizar evaluación social.
} 
decisiones de quienes las formulan, seleccionan y ejecutan. Del mismo modo, sirve para afinar o mejorar los criterios de selección y evaluación de políticas futuras.

Crear una cultura de proyectos en El Salvador, definitivamente requiere de considerables recursos económicos, humanos, conocimiento (Know How), etc. Sin embargo, es necesario comenzar a trabajar en esta línea y, en lugar de poner la escasez de recursos como pretexto para no crear y desarrollar esa cultura, buscar creativamente formas de procurar lo necesario para iniciar ya. En caso de que la creatividad no diera para mucho, la vasta literatura aquí comentada proporciona ideas y propuestas concretas para proveer los fondos necesarios para ese propósito.

En materia de cooperación externa, los organismos financieros multilaterales, con la experiencia de despilfarro y de ineficientes asignaciones de recursos muy conocida por ellos, es muy probable que inviertan fondos para crear la cultura de proyectos en sus países "beneficiarios". El BID, por ejemplo, ha contribuido preparando a distintas generaciones de profesionales en el área de la economía del bienestar, financiando estudios de especialización, cursos cortos, pasantías, postgrados (maestrías, doctorados y postdoctorados) en universidades y en centros de investigación de mucho prestigio y reconocidos por su experiencia en el área de asignación de recursos.

Países como Chile, Colombia, España, México y otros, así como organismos no financieros de cooperación e institutos de inves- tigación regional, otorgan oportunidades para formar y capacitar a profesionales en el proceso de formulación y evaluación de políticas públicas. Pero para aprovechar estas oportunidades, se necesita institucionalizar el proceso de evaluación, lo que requiere voluntad política. Nuevamente, el balón está en la cancha de los políticos, porque otro dicho popular también reza: "En río revuelto, ganancia de pescadores".

\section{Referencias}

- Banco Central de Reserva de El Salvador (Agosto 2010). Boletín Estadístico mensual."

- Castro Rodríguez, Raúl y Mokate, Karen Marié (2000). Evaluación económica de proyectos de inversión. Santafé de Bogotá. Ediciones Uniandes.

- El Diario de Hoy (2010, 3 de octubre). "Estado sigue endeudándose: País debe $\$ 11$ mil Mlls". Recuperado de http:// www.elsalvador.com/mwedh/nota/nota_completa.asp?idC at $=6374 \&$ idArt $=5195864$

- Feinstein, Osvaldo. "Evaluación programática de políticas públicas". En Evaluación de Políticas Públicas. ICE. Mayo-Junio de 2007.

- Vera Hernández, Marcos (2010). "The Evaluation of Public Policies". Recuperado de http://www.homepages.ucl.ac.uk/ uctpamv

- Ysa, Tamyko (2010). Evaluación de políticas públicas. Instituto de Dirección y Gestión Pública (Esade). Recuperado de http://www.gencat.cat/economia/doc/doc_22376634_ 1.pdf. 